\title{
Seasickness and its impact on researchers' work on board French oceanographic vessels
}

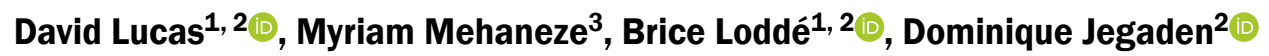 \\ ${ }^{1}$ Centre for Professional and Environmental Pathologies, Morvan Teaching Hospital (CHRU), Brest, France \\ ${ }^{2}$ French Society for Maritime Medicine, Faculty of Medicine and Health Sciences, University of Western Brittany, Brest, France \\ ${ }^{3}$ Centre for Occupational Medicine (Santé au Travail en Iroise), Brest, France
}

\begin{abstract}
Background: Seasickness (SS) is an often hidden pathology, but one that can significantly disrupt work on board. The aim of the study is to evaluate the influence of SS on the workability of workers on board vessels. Materials and methods: We performed a cross-sectional questionnaire study conducted on 250 oceanographers in 2015 during 3 months. Based on the "Bos seasickness susceptibility questionnaire", we created a specific questionnaire with 49 questions.

Results: 151 men and 72 women responded to the survey. 188 of them $(91.7 \%$ of women and $80.8 \%$ of men) report being seasick, either occasionally (69\%) or at each boarding where there is female predominance (23.6\% vs. $11.3 \%$ for men). The major symptoms are nausea (82\%) and vomiting (56\%). $60 \%$ of the workers think that SS has an influence on the success of their mission, by first affecting their mood (50\%), relationship (23\%), and increased risk of accidents such as falls, accidents on machines or in laboratories (40\%). Antinaupathic treatments also produce deleterious effects on their workstation. Women have higher risk of developing SS (odds ratio [OR] 2.6; 95\% confidence interval [CI] 1.03-6.6; $p=0.04$ ), more frequently taking medicines when ill (OR 4.1; 95\% $\mathrm{Cl} 1.27-13.2 ; p=0.004)$ and coming with her own tablets (OR 2.3; 95\% Cl 1.3-4.1; $p=0.04$ ).

Conclusions: Gender is a trending factor of SS. Information on SS clinical signs, impact and therapeutics could be prone to prevent sickness and impact of it on workability.
\end{abstract}

(Int Marit Health 2020; 71, 3: 160-165)

Key words: maritime medicine, seasickness, onboard conditions

\section{INTRODUCTION}

On board a ship, in addition to its own movement related to its propulsion and like for all nonstable natural environment, the sea could induce various movements back and forth (pitch) and from right to left (roll). This complex and random system of very low frequency vibratory type, due to changing weather conditions, is variable in time, frequency and intensity. The main result is a vertical translational movement directly related to waves' height. The frequency of these vibrations is between $0.01 \mathrm{~Hz}$ in very calm condition and $1.5 \mathrm{~Hz}$ in bad weather and accelerations range from 0.01 to $0.8 \mathrm{~g}$, sometimes even $1 \mathrm{~g}$. At these frequencies, the body behaves like a single mass and the vibrations are fully transmitted in amplitude and acceleration (whole body vibrations) [1].
O'Hanlon and McCauley [2] have shown that, more than roll and pitch, which would ultimately play a secondary role, the primary cause of seasickness (SS) is above all the acceleration of the vertical component of the movements. An abacus drawn from the theory of these authors was modelled by Bos and Bles [1]. They compiled the frequency of the movement (in Hertz [Hz]), the acceleration (in $\mathrm{m} / \mathrm{s}^{2}$ ) and the motion sickness incidence (MSI = percentage of subjects presenting a vomiting within $2 \mathrm{~h}$ ) [1]. Thus, the maximum MSI would be reached for a movement frequency of $0.16 \mathrm{~Hz}$ and an acceleration of $5.4 \mathrm{~m} / \mathrm{s}^{2}$. Lawther and Griffin [3] and after Davis and Hollowey [4] confirmed that the MSI was directly dependent on waves' height and proportional to the movements' vertical acceleration. 
Seasickness is a consequence of a body positioning information disorder, involving simultaneously three components: the vestibular system; the visual system, in particular tracking; and the proprioceptive and somatosensory system, in particular feet and nape of neck. The information produced by these three systems, transmitted to the brain centres, is compared with each other, but also compared with the information previously stored, to evaluate their coherence, which involves an adequate motor reaction of equilibration when they are coherent. In the case of SS, this information is conflicting and results in the appearance of clinical signs (sensory rearrangement theory of Reason and Brand [5]).

The chronology, number and intensity of the symptoms could be different in a very marked way according to the individual susceptibility of the individuals, the size of the ship, the nature, duration and importance of the movement and the environmental conditions (odours, heat, onboard places, position of the body and psychological conditions). We classically distinguish three phases: the beginning phase (anxiety, pallor, cold sweats, yawning, salivation, and drowsiness), the state phase (nausea, vomiting and prostration) and evolution (in general resolution of signs within a few hours). In rare cases, the process can lead to acute dehydration, imbalance of a preexisting health disorder such as diabetes, or disruption of treatment (not taking medication or rejection by vomiting).

Most studies and articles published in the field of motion sickness talked about road and air transport. Some also discussed about the mal du debarquement syndrome but SS in seafarers' population is rarely discuss. Few studies have been published on the influence of SS and time to get used to life at sea on the workability of workers on board vessels.

The objectives of this study were to test certain epidemiological data found in the SS literature (prevalence, differences in relation to sex, study of clinical signs) and above all to assess the medical, economic and relational impact of this pathology on the implementation of professional tasks on board, highlighting the possible differences between men and women.

We studied these questions in a population of oceanographic researchers from a French research centre.

\section{MATERIALS AND METHODS}

\section{SURVEY METHODOLOGY}

This is cross-sectional questionnaire study was conducted on 250 oceanographers in 2015 during 3 months. Based on the "Bos seasickness susceptibility questionnaire" [6], we created a specific questionnaire with 49 questions. Before the survey and during an onboard mission, it was tested in a smaller population. A health unit with an occupational nurse and a physician was located in the research centre.
According to the health policies of the occupational health service, all workers who had onboard worktimes had been referred to the health unit for annual medical examinations. In 2014, during examinations, employees of the health unit inform workers about the survey. In 2015, the questionnaires were sent individually by email. Workers had to send it back to the occupational health. They gave it in hand to hand to the nurse and confirm their consent. The inclusion criteria were: volunteer, being a researcher or a technician from the French research institute, regular onboard mission, fit at work and for navigation [7]. The onboard periods were either coastal or longer ocean-going missions.

\section{STATISTICAL ANALYSIS}

Statistical analysis was done by using Statistica software (TIBCO data sciences, Palo Alto California, USA). The quantitative variables were described using the usual position and standard deviations. Categorical variables were presented as numbers (percentage). When conditions applied, the t-test was used. When needed, the Shapiro-Wilk test was used to test for normal distribution of data. Where variables were not normally distributed, non-parametric test (Mann-Withney $U$ test) were used, otherwise. Crude odds ratio (OR) including 95\% confidence interval $(\mathrm{Cl})$ were calculated by binary regression. The alpha risk was set at $5 \%$ for all analyses.

\section{RESULTS}

\section{DATA COLLECTION}

The source population included 250 workers: oceanographers are researchers from different specialties (biologists, geologists, oceanographers, climatologists, physicists, chemists) who are interested in all aspects of the marine environment. We collected 223 questionnaire (151 men and 72 women), for a satisfactory response rate of $89.2 \%$.

The population and missions characteristics are summarised in Table 1.

Frequency, characteristics of SS and environmental factors effects are listed in Table 2.

Table 1. Characteristics of population and onboard missions

\begin{tabular}{lll}
\hline & Number & Per cent \\
\hline Men & 151 & 67.7 \\
Women & 72 & 32.3 \\
Coastal and offshore & 136 & 61 \\
Offshore & 58 & 26 \\
Coastal & 29 & 13 \\
1 to 2 missions & 133 & 59.6 \\
$>$ 2 missions & 90 & 40.9 \\
Total & 223 &
\end{tabular}


Table 2. Frequency, characteristics and environmental factors effects on seasickness

\begin{tabular}{|c|c|c|c|}
\hline & & Number & Per cent \\
\hline \multirow[t]{2}{*}{ Seasickness } & Yes & 188 & 84.3 \\
\hline & Never & 35 & 15.7 \\
\hline \multirow[t]{2}{*}{ Frequency } & Sometimes & 154 & 81.9 \\
\hline & Every time & 34 & 18.1 \\
\hline \multirow[t]{3}{*}{ With sea conditions } & Yes & 166 & 89.2 \\
\hline & No & 20 & 10.8 \\
\hline & Total & 186 & \\
\hline \multirow[t]{3}{*}{ Vertical movements of the ship } & Yes & 145 & 78.4 \\
\hline & No & 36 & 19.5 \\
\hline & Total & 185 & \\
\hline \multirow[t]{2}{*}{ Roll movements of the ship } & Yes & 92 & 50 \\
\hline & No & 74 & 40.2 \\
\hline \multirow[t]{2}{*}{ When first symptoms begin } & After some hours & 167 & 88.8 \\
\hline & Immediately after embarkment & 20 & 10.6 \\
\hline \multirow[t]{2}{*}{ Do you need time for getting used to the sea } & Yes & 165 & 88.2 \\
\hline & No & 22 & 11.8 \\
\hline \multirow[t]{4}{*}{ When symptoms disappeared } & $2 / 3$ days & 81 & 44 \\
\hline & 1 day & 43 & 23.4 \\
\hline & Few hours & 34 & 18.5 \\
\hline & Never & 26 & 14.1 \\
\hline \multirow[t]{4}{*}{ Symptoms are increased by } & Smell of gasoil & 136 & 88.9 \\
\hline & Smell of cooking & 83 & 54.2 \\
\hline & Smell of tobacco & 80 & 53.2 \\
\hline & Poor ventilation & 54 & 35.2 \\
\hline \multirow[t]{3}{*}{ Influence of menstruation period } & Don't know & 45 & 62.5 \\
\hline & No & 20 & 27.8 \\
\hline & Yes & 7 & 9.7 \\
\hline
\end{tabular}

Vomiting is the highest stage of SS and allows patients to be counted on a common basis (MSI). The Tables 3 and 4 demonstrates respectively the SS symptoms, the impact of SS on workability and missions declared by workers.

When comparing two groups by gender, we find significant differences for SS (OR 2.6; 95\% Cl 1.03-6.6; $p=0.04)$, increased frequency in women for taking medicines when ill and coming with her own tablets (respectively OR 4.1; 95\% Cl 1.27-13.2; $p=0.004$ and OR 2.3; 95\% Cl 1.3-4.1; $p=0.04$ ) (Table 5).

Average boarding times were much lower for coastal missions ( 7.8 days) compared to offshore missions ( 25.7 days, $p=0.05)$.

\section{FREQUENCY OF SEASICKNESS}

The occurrence of SS was not related to the number of days on board ( 18 days for agents prone to SS and 21 days for the others, $p=0.1)$, age $(p=0.7)$ nor to the type of navigation (83.5\% for offshore, $89.7 \%$ in coastal, $p=0.86$ ).
Table 3. Declared symptoms of seasickness in percentage

$\begin{array}{ll}\text { Nausea } & 81.9 \% \\ \text { Vomiting } & 55.9 \% \\ \text { Pallor } & 43.1 \% \\ \text { Yawning } & 42.6 \% \\ \text { Cold sweats } & 40.4 \% \\ \text { Drowsiness } & 38.3 \% \\ \text { Fatigue } & 35.6 \% \\ \text { Work disinterest } & 35.1 \% \\ \text { Listlessness } & 17 \% \\ \text { Withdrawal } & 16.5 \% \\ \text { Headaches } & 16.5 \% \\ \text { Dizziness } & 12.8 \% \\ \text { Balance impairment } & 6.9 \% \\ \text { Sopite syndrome } & 2.6 \%\end{array}$


Table 4. Impact of seasickness (SS) on workability

\begin{tabular}{|c|c|c|c|}
\hline & & Number & Per cent \\
\hline \multirow[t]{2}{*}{ Are you afraid of SS before embarkment } & No & 164 & 85.4 \\
\hline & Yes & 28 & 14.6 \\
\hline \multirow[t]{2}{*}{ Due to $\mathrm{SS}$, have you refused a mission } & No & 183 & 95.8 \\
\hline & Yes & 8 & 4.2 \\
\hline \multirow[t]{2}{*}{ Does SS have an impact on your mission? } & Yes & 118 & 62.1 \\
\hline & No & 72 & 37.9 \\
\hline \multirow[t]{4}{*}{ What kind? } & My own mood & 86 & 75.4 \\
\hline & Economical & 43 & 37.7 \\
\hline & Relationship with colleagues & 33 & 28.9 \\
\hline & Hard relationship with head of mission & 5 & 4.4 \\
\hline \multirow[t]{4}{*}{ In case of SS what do you do? } & Go on deck & 106 & 56.4 \\
\hline & Stay in my cabin & 99 & 52.7 \\
\hline & Take medicines & 79 & 42 \\
\hline & Nothing special & 25 & 13.3 \\
\hline \multirow[t]{5}{*}{ Type of medication } & Nothing & 85 & 45.9 \\
\hline & Mercalm & 53 & 28.6 \\
\hline & Scopolamine patches & 40 & 21.6 \\
\hline & Other: homeopathy, food and beverages & 18 & 9.7 \\
\hline & Stugeron & 3 & 1.6 \\
\hline \multirow[t]{2}{*}{ Do you feel embarrassed by SS } & No & 119 & 64 \\
\hline & Yes & 67 & 36 \\
\hline \multirow[t]{3}{*}{ What is the most embarrassing? } & Less reactive and active at work & 61 & 88.4 \\
\hline & To be sick in professional place & 29 & 42 \\
\hline & My colleagues could see me vomiting & 18 & 26.1 \\
\hline \multirow[t]{2}{*}{ Is SS have an impact on your time at workplace } & Yes & 95 & 50.8 \\
\hline & No & 92 & 49.2 \\
\hline
\end{tabular}

Table 5. Comparison by gender

\begin{tabular}{lllll}
\hline & Man & Woman & Odds ratio & P \\
\hline Seasickness* (yes) & $122(80.8 \%)$ & $66(91.7 \%)$ & $2.6[1.03-6.6]$ & 0.004 \\
Coastal missions & $19(12.6 \%)$ & $10(13.9 \%)$ & $2.2[0.86-5.4]$ & 0.09 \\
Coastal and offshore & $105(69.5 \%)$ & $31(43.1 \%)$ & $0.56[0.23-1.33]$ & 0.18 \\
Symptoms & & & \\
Stop after few hours & $17(14.3 \%)$ & $17(26.2 \%)$ & $2.3[0.9-5.88]$ & 0.08 \\
Stop after 2 days & $58(45.7 \%)$ & $23(35.4 \%)$ & $0.91[0.4-2]$ & 0.8 \\
Never stop & $14(11.8 \%)$ & $12(18.5 \%)$ & $1.97[0.72-5.42]$ & 0.18 \\
Afraid before mission (yes) & $14(11.3 \%)$ & $14(20.6 \%)$ & $2.03[0.9-4.57]$ & 0.08 \\
Take medicines* (yes) & $44(35.8 \%)$ & $35(53.8 \%)$ & $4.1[1.27-13.2]$ & 0.001 \\
Come with my own medicines (yes) & $52(36.4 \%)$ & $41(53.9 \%)$ & $2.3[1.3-4.1]$ & 0.004 \\
No embarkation because of SS (yes) & $4(3.2 \%)$ & $4(6 \%)$ & $0.52[0.12-2.1]$ & 0.37 \\
Does SS have an impact on your mission? (no) & $45(36.6 \%)$ & $27(40.3 \%)$ & $1.17[0.63-2.15]$ & 0.61 \\
Concentration at work (no) & $65(52.8 \%)$ & $30(46.9 \%)$ & $1.27[0.69-2.32]$ & 0.4 \\
Do you feel embarrassed by SS & $41(33.3 \%)$ & $26(41.3 \%)$ & $1.4[0.75-2.62]$ & 0.28 \\
*p 0.05 & & & &
\end{tabular}

${ }^{*} p<0.05$ 
Table 6. Medicines

\begin{tabular}{llll} 
& Man & Woman & Total \\
\hline Dimenhydrinate & $18.5 \%$ & $34.7 \%$ & $23.8 \%$ \\
Cinnarizine & $2 \%$ & $0 \%$ & $1.4 \%$ \\
Scopolamine's patch & $13.3 \%$ & $27.8 \%$ & $17.9 \%$ \\
Other (acupuncture, homeopathy) & $7.3 \%$ & $9.7 \%$ & $8.1 \%$ \\
Are medicines efficient yes & $75 \%$ & $84 \%$ & $79 \%$
\end{tabular}

\section{TAKING ANTI-SICKNESS TREATMENT}

Table 6 summarises the behaviours implemented during the occurrence of a naupathy. The most widely used conventional treatments were dimenhydrinate and cinnarizine (only $1 \%$ for the latter molecule because it is not marketed in France, despite its recognized effectiveness) for treatments in tablets and scopolamine per patch $[6,7]$.

\section{DISCUSSION}

The high level in response rate allows us to discuss our results.

We found, consistently to literature on the subject, gender susceptibility for SS and mostly gastrointestinal disorders. Due to SS, women are also more anxious before mission and taken medicines, but they less declared than men impact on work (concentration at work, psychological disorders).

Due to extreme variability of its occurrence' conditions it is hard to collect quantitative data on the incidence and prevalence of this pathology. Indeed, the weather, sea conditions and number of patients during each mission are various. The estimated prevalence ranged from $25 \%$ to $30 \%$ of American and British white populations in calm sea, increasing between $50 \%$ and $90 \%$ in heavy sea [8]. A recent publication on sailors from the French Merchant Navy gives a figure of $55 \%$ of sailors who would not be affected by SS at all [9]. In our study we found respectively a prevalence of $84 \%$ and $69 \%$ for "occasionally or systematically" and "occasionally" SS suffering. Lower frequency and duration of onboard mission in researchers could explain it. Consistent with our results, gastrointestinal symptoms were more frequently declared with nausea (61\%) and vomiting (48\%) followed by yawning and drowsiness (30\%) in the study involved by Turner and Griffin [10] or incidence of vomiting of $40 \%$ in 4915 passengers during 17 trips $[8,10]$. Various percentages for apathy, fatigue and cold sweats are described [10]. But data in literature is based either on a calculation of the MSI in specific conditions [10]. In 1976, Graybiel and Knepton [11] isolated a particular type of motion sickness, sopite syndrome, associating drowsiness, yawning, disinterest in work, mood disorders, sleep disorders, but without digestive signs. We can classify in this syndrome only 5 people ( 2 men and 3 women).
Confirmed by our study, it is generally accepted that women are more often affected by SS than men $[12,13]$. Our results shed particular light on this point by showing significant differences with an OR at 2.6. Moreover, some studies show a relationship between menstrual period and SS [14]. In our results, only $10.6 \%$ of women expressed greater sensitivity to SS during menstruation, 30\% reported none. According to Cuomo-Granston and Drummond [15] female sex hormones may, at least in part, predispose individuals susceptible to motion sickness and migraine.

In addition, adaptation to maritime conditions plays a role here. Sailors regularly on board are generally less prone to SS than passengers, since they incorporate movement patterns conforming to the theory of Reason and Brand [5]. Like described by Bos and Bles [1] the effect of gender on SS susceptibility decreased inversely with age and no differences after 35 years were noted.

Seasickness first poses a problem of self-esteem and relationships with others. In popular imagination, a seafarer is not (or should not be) prone to SS and, therefore, is prone to easily mock passengers affected by SS. The sick person therefore feels in a situation of psychological inferiority vis-à-vis those who are not or who do not want to admit it. In our population, $17 \%$ find it humiliating to be forced to vomit in front of work colleagues and $20 \%$ declared having their relationship disrupted. It could also explain why women significantly come with their own medicines against SS and taken it more frequently than men who have to be "stronger" against SS.

Seasickness and susceptibility to SS have a direct and indirect impact on workability. When they were ill, onboard workers went on deck or stayed in their cabin and daily time at work decrease. Indeed, most of workers declared that SS have an impact on their work tasks, concentration at work and own mood. Pisula et al. [16] have showed that vertical accelerations can cause cognitive impairment. Matsangas and McCauley [17] believe that the stress caused by SS and sopite syndrome is, in part, responsible for the deterioration of cognitive performance. Valk mentions the fatigue and sleep disturbances caused by SS in the decline in performance rather than the movements of the ship itself [18]. The causes of SS accidents are in the risk of falling 
(especially overboard while vomiting). But, whether in falls or in accidents at work such as accidents on machine tools or launching devices, or even jets of chemicals, it is mainly the movements of the ship, by bad time, which carry the risk, more than SS. In his thesis on 61 Finnish sailors, Spätgens [19] notes that $10 \%$ of them had SS at some point which prevented them from carrying out their usual tasks on board, $11 \%$ could only do light work, $38 \%$ had moderate discomfort in their work station and $42 \%$ were able to fully perform their tasks.

Side effects of drugs taken for SS could impact work capacities. Gordon [20] has shown that dimenhydrinate disrupts reaction and memorisation tests like digit span, which is not the case with cinnarizine and scopolamine. Also drowsiness and blurred vision have been noticed with such medicines.

To prevent impact of SS on work non-drug treatments such as optokinetic rehabilitation could be discussed. It gives good lasting results over time, and which can be proposed for subjects with uncontrollable SS $[20,21]$. This treatment requires 20 sessions over a period of 3 months in a specialised environment. According to the authors, $71 \%$ of reeducated subjects are improved, compared to $12.5 \%$ of subjects subjected to placebo treatment [22]. It allows you to be less prone to SS and not taking medication during the mission. This therapy could also benefit to workers who declared higher susceptibility to SS.

Our study is a self-declared study by questionnaire. A healthy worker effect is a possible bias with a population of selected oceanographers who regularly embarked. Indeed, in popular imagination, a seafarer is not (or should not be) prone to SS and, therefore, is prone to easily mock passengers affected by SS. The sick person therefore feels in a situation of psychological inferiority and do not declared it.

\section{CONCLUSIONS}

Seasickness is an often hidden pathology, but one that can significantly disrupt work on board. Gender is a trending factor of SS. Information on SS clinical signs, impact and therapeutics could be prone to prevent sickness, other diseases linked to or imbalanced by SS and impact of it on workability.

\section{REFERENCES}

1. Bos JE, Bles W. Modelling motion sickness and subjective vertical mismatch detailed for vertical motions. Brain Res Bull. 1998; 47(5): 537-542, doi: 10.1016/s0361-9230(98)00088-4, indexed in Pubmed: 10052585.

2. O'Hanlon JF, McCauley ME. Motion sickness incidence as a function of the frequency and acceleration of vertical sinusoidal motion. Aerosp Med. 1974; 45(4): 366-369, indexed in Pubmed: 4821729.

3. Lawther A, Griffin MA. survey of the occurrence of motionsickness amongst passengers at sea. Aviat Space Environ Med. 1988; 59: 399-406.

4. Davis MR, Holloway DS. The influence of hull form on the motions of high speed vessels in head seas. Ocean Eng. 2003; 30(16): 2091-2115, doi: 10.1016/s0029-8018(03)00045-3.
5. Reason JT, Brand JJ. Motion sickness. Academic Press, Oxford, England 1975.

6. Bos JE, Damala D, Lewis C, et al. Susceptibility to seasickness. Ergonomics. 2007; 50(6): 890-901, doi: 10.1080/00140130701245512, indexed in Pubmed: 17457748.

7. Jégaden D, Dewitte JD, Loddé B. L'aptitude à la navigation maritime: une véritable évaluation des risques de maladie. Arch Mal Prof Environnement. 2005; 66(4): 318-325, doi: 10.1016/s17758785(05)79100-1.

8. Chan G, Moochhala C, Zhao B, et al. A comparison of motion sickness prevalence between seafarers and non-seafarers onboard naval platforms. Int Marit Health. 2006; 57(1-4): 56-65.

9. Grovel A, Stevanovic J, Maruani M. Travailler à bord des navires de la marine marchande. Etude sociologique des risques et des violences physiques, psychologiques ou a caractere sexuel; 2017 [Document IRES].

10. Turner M, Griffin MJ. Motion sickness incidence during a round-the-world yacht race. Aviat Space Environ Med. 1995; 66(9): 849-856, indexed in Pubmed: 7487823.

11. Graybiel A, Knepton J. Sopite syndrome: a sometimes sole manifestation of motion sickness. Aviat Space Environ Med. 1976; 47(8): 873-882, indexed in Pubmed: 949309.

12. Lawther A, Griffin MJ. The motion of a ship at sea and the consequent motion sickness amongst passengers. Ergonomics. 1986; 29(4): 535-552, doi: 10.1080/00140138608968289, indexed in Pubmed: 3709507.

13. Reschke MF, Cohen HS, Cerisano JM, et al. Effects of sex and gender on adaptation to space: neurosensory systems. J Womens Health (Larchmt). 2014; 23(11): 959-962, doi: 10.1089/jwh.2014.4908, indexed in Pubmed: 25401941.

14. Matchock RL, Levine ME, Gianaros PJ, et al. Susceptibility to nausea and motion sickness as a function of the menstrual cycle. Womens Health Issues. 2008; 18(4): 328-335, doi: 10.1016/j. whi.2008.01.006, indexed in Pubmed: 18485739.

15. Cuomo-Granston A, Drummond PD. Migraine and motion sickness: what is the link? Prog Neurobiol. 2010; 91(4): 300-312, doi: 10.1016/j.pneurobio.2010.04.001, indexed in Pubmed: 20416353.

16. Pisula PJ, Lewis $\mathrm{CH}$, Bridger RS. Vessel motion thresholds for maintaining physical and cognitive performance: a study of naval personnel at sea. Ergonomics. 2012; 55(6): 636-649, doi: 10.1080/00140139.2012.657249, indexed in Pubmed: 22455510.

17. Matsangas P, McCauley ME, Becker W. The effect of mild motion sickness and sopite syndrome on multitasking cognitive performance. Hum Factors. 2014; 56(6): 1124-1135, doi: 10.1177/0018720814522484, indexed in Pubmed: 25277021.

18. Valk P, Grech M, Bos JA. multi-factorial analysis of human performance during a 9-day sea trial. International Conference on Human Performance at Sea, Glasgow. 2010.

19. Spatgens P. Seasickness amongst less experienced seafarers. Finlande: University of Turku, Finland; 2016 [Thesis].

20. Gordon CR, Gonen A, Nachum Z, et al. The effects of dimenhydrinate, cinnarizine and transdermal scopolamine on performance. J Psychopharmacol. 2001; 15(3): 167-172, doi: 10.1177/026988110101500311, indexed in Pubmed: 11565623.

21. Trendel D, Haus-Cheymol R, Erauso T, et al. Optokinetic stimulation rehabilitation in preventing seasickness. Eur Ann Otorhinolaryngol Head Neck Dis. 2010; 127(4): 125-129, doi: 10.1016/j. anorl.2010.07.006, indexed in Pubmed: 20860921.

22. Ressiot E, Dolz M, Bonne L, et al. Prospective study on the efficacy of optokinetic training in the treatment of seasickness. Eur Ann Otorhinolaryngol Head Neck Dis. 2013; 130(5): 263-268, doi: 10.1016/j.anorl.2012.03.009, indexed in Pubmed: 23562228. 